\title{
Pattern of Fungal Dermatoses Investigations in Upth: A Five-Year Review
}

\author{
Awopeju Temitayo Oluwajenyo ${ }^{1}$, Bolaji Otike-Odibi ${ }^{2,}$, , Dasetima Altraide ${ }^{3}$ \\ ${ }^{1}$ Department of Medical Microbiology and Parasitology, University of Port-Harcourt Teaching Hospital, Port Harcourt, Rivers State, Nigeria \\ ${ }^{2}$ Dermatology Unit, Department of Internal Medicine, Faculty of Clinical Sciences, University of Port-Harcourt, Rivers State, Nigeria \\ ${ }^{3}$ Dermatology Unit, Department of Medicine, Faculty of Clinical Sciences, University of Port Harcourt, Rivers State, Nigeria
}

\section{Email address:}

Bolajio_o@yahoo.com (B. Otike-Odibi)

${ }^{*}$ Corresponding author

\section{To cite this article:}

Awopeju Temitayo Oluwajenyo, Bolaji Otike-Odibi, Dasetima Altraide. Pattern of Fungal Dermatoses Investigations in Upth: A Five-Year Review. Central African Journal of Public Health. Vol. 7, No. 2, 2021, pp. 61-64. doi: 10.11648/j.cajph.20210702.13

Received: March 4, 2021; Accepted: March 22, 2021; Published: March 30, 2021

\begin{abstract}
Background: Infectious dermatoses are rife in resource limited settings. Fungi skin infection constitutes the majority of infective skin conditions seen by physicians in primary, secondary, and tertiary health care centers, in Nigeria. Methods: A retrospective five-year review of the pattern of fungal dermatoses investigations among patients attending the University of Port Harcourt Teaching Hospital between 2015 - 2020 was carried out. Results: There were five hundred and fifty-five (555) patients referred for fungal investigations over the five-year period. The data showed that most of the patients referred for fungal investigations were between $21-30$ years $(36.4 \%)$ and $31-40$ years $(18.2 \%)$ respectively. Most of the patients were observed to be female $(57.1 \%)$. The bulk of the referrals originated from the dermatology/medical outpatient clinic (90.3\%). About 45\% (252/555) of the referrals was observed to have fungal growth. The most common fungi isolated was Aspergillus sp (41.67\%) and Candida sp (35.3\%) with Blastomyces spp and Fusarium spp being the least isolated fungi $(0.4 \%$ each). Conclusion: The study showed that the pattern of dermatoses was not significantly associated with age or gender. Superficial fungi infections still need to be addressed as a public health problem among the growing populace of Nigeria. Similarly, there seem to be a relative increase in the prevalence of skin infections among elderly people in the period under review.
\end{abstract}

Keywords: Dermatoses, Microbiology, Skin Infection, Fungal

\section{Introduction}

Skin diseases have always maintained a place of relevance in health care delivery spanning from primary to tertiary health care in developing countries. The ratio of a dermatologist to a patient in most developing countries is low due to scarcity of specialists in this area and the enormous population. Many of the dermatologists involved in daily clinical work in these parts of the world are in the big cities and cases in rural areas need to be referred to the cities before they can access skin care. This applies to South and Central America, Asia and Africa [1,2]. This results in poor coverage for dermatological services in many parts of Nigeria.

Promoted by poverty and the typically tropical climate, infectious dermatoses are rife in resource limited settings. [1,
2] A number of these dermatoses are cutaneous manifestations of neglected tropical diseases (NTDs), communicable diseases which occur among one billion of the most impoverished populations in the developing world [35]. Fungi skin infection constitutes the majority of infective skin conditions seen by physicians in primary, secondary, and tertiary health care centers, in Nigeria [6-8]. In some cases such as the dermatophytoses, clinical diagnosis is straightforward but laboratory identification is necessary to direct treatment and institute prophylactic measures [9-11]. These reasons place a premium on the clinical microbiology laboratory in the management of infectious dermatoses. Most of the diagnoses of skin diseases are made by primary care physicians as they are usually the first contact with the patient in the hospitals. The availability of accurate baseline data for planning intervention can only however be based on 
expert dermatological services provided mainly in tertiary hospital settings where diagnosis of lesions can be confirmed by laboratory support. Different studies have reported various patterns of skin diseases in Nigeria [6-10]. however, information on the pattern of fungal skin diseases in SouthSouth of Nigeria is almost nonexistent. This study was carried out to establish the pattern of fungal dermatoses in a tertiary healthcare setting, in Port Harcourt, Rivers state.

\section{Methods}

\subsection{Study Area}

The study was carried out at the University of Port Harcourt Teaching Hospital, Rivers state, Nigeria. The Hospital is a 700 - bed capacity tertiary hospital that serves as a referral center for other healthcare institutions in the state and neighboring states including Bayelsa and Abia states.

\subsection{Study Design}

A five-year retrospective assessment of investigations for fungal dermatoses at the Department of Medical Microbiology of the University of Port Harcourt Teaching Hospital between 2015 to 2020 was carried out.

\subsection{Ethical Consideration}

Ethical approval was obtained from the research and ethics committee of the University of Port Harcourt Teaching Hospital, prior to the commencement of the study. No personal identifying information was collected in the course of the study.

\subsection{Data Collection}

A PROFORMA data collection sheet was used to collect demographic information, referral information and laboratory findings of the patients referred to the Microbiology department for fungal investigations.

\subsection{Data Analysis}

The data collected was entered into an electronic spreadsheet and processed appropriately. Descriptive statistics (mean, frequency and percentage) was used to present the data as appropriate. The distribution of fungal growth by the demographic information was assessed using the Chi-square statistic. All analysis was done at a 95\% confidence interval and a p-value less than 0.05 was considered significant.

\section{Results}

Table 1 shows the demographic distribution of the patients referred for fungal investigations. The investigation analysed is the skin scraping for mycology... Seventy-six $(13.7 \%)$ of the patients were between $1-10$ years, $59(10.6 \%)$ were between $11-20$ years, 202
(36.4\%) were between 21 - 30 years old, $101(18.2 \%)$ were between $31-40$ years old, $56(10.1 \%)$ were between $41-50$ years old, $31(5.6 \%)$ were between $51-60$ years old and $30(5.4 \%)$ were 60 years and above. The mean age of the patients was $28.7 \pm 16.2$ years. There were 238 $(42.9 \%)$ male and $317(57.1 \%)$ female patients. The dermatology clinic had the greatest number of referrals (90.3\%), followed by the Female medical ward (3.8\%) and the Ear, Nose and Throat Ward (2.9\%).

Table 1. Demographic distribution.

\begin{tabular}{lll}
\hline & Frequency $(\mathbf{n}=\mathbf{5 5 5})$ & Percent $\mathbf{( \% )}$ \\
\hline Age groups (years) & & \\
$1-10$ & 76 & 13.7 \\
$11-20$ & 59 & 10.6 \\
$21-30$ & 202 & 36.4 \\
$31-40$ & 101 & 18.2 \\
$41-50$ & 56 & 10.1 \\
$51-60$ & 31 & 5.6 \\
60 and above & 30 & 5.4 \\
Mean Age & $28.7 \pm 16.2$ years & \\
Gender & & \\
Male & 238 & 42.9 \\
Female & 317 & 57.1 \\
Ward & & \\
CHEW & 1 & 0.2 \\
A \&E & 2 & 0.4 \\
MMW & 3 & 0.5 \\
CHOP & 11 & 2.0 \\
ENT & 16 & 2.9 \\
FMW & 21 & 3.8 \\
DERMATOLOGY & 501 & 90.3 \\
\hline
\end{tabular}

CHEW; Children emergency ward, A\&E: Accident and Emergency, MMW; Male Medical Ward, CHOP: Children outpatient ward, ENT: Ear Nose and Throat Ward, FMW; Female Medical Ward.

Figure 1 shows the prevalence of fungal growth observed among the patients. There was $45.4 \%(252 / 555)$ prevalence of fungal growth among the patients.

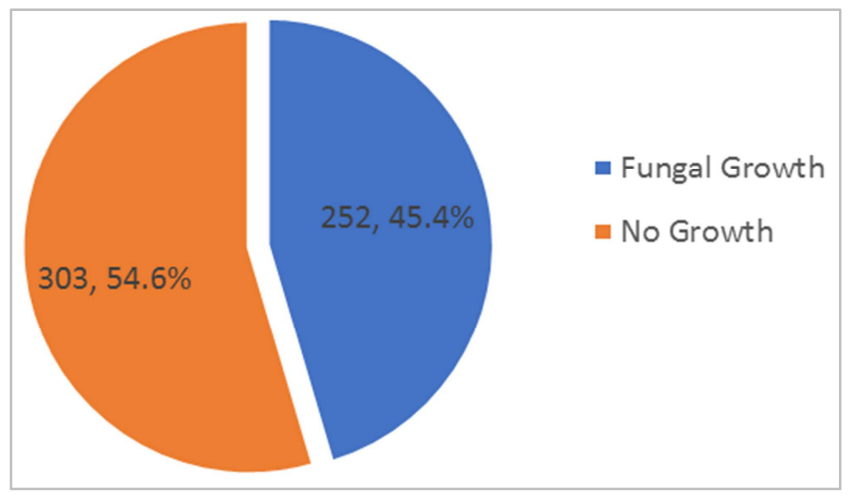

Figure 1. Prevalence of Fungal Growth.

Table 2 shows the distribution of fungal growth by demographic data. The highest frequency of fungal growth was observed among subjects between 21-30 years old (33.99\%) followed by subjects between $31-40$ years old $(17.49 \%)$. The least frequency of fungal growth was observed in patients between $51-60$ years old $(4.62 \%)$. The distribution of fungal growth by gender also showed that the 
female patients had the highest distribution of fungal growth (56.44\%) compared to the male patients $(43.56 \%)$.

Table 2. Relationship of demographic factors and presence of fungal growth.

\begin{tabular}{|c|c|c|c|}
\hline Variables & $\begin{array}{l}\text { Fungal growth } \\
n=252,(\%)\end{array}$ & $\begin{array}{l}\text { No fungal growth } \\
\mathrm{n}=303,(\%)\end{array}$ & $\begin{array}{l}\text { Chi-square } \\
\text { (p-value) }\end{array}$ \\
\hline \multicolumn{4}{|c|}{ Age groups (years) } \\
\hline $1-10$ & $31(12.3)$ & $45(14.85)$ & \multirow{7}{*}{$5.33(0.501)^{* *}$} \\
\hline $11-20$ & $23(9.13)$ & $36(11.88)$ & \\
\hline $21-30$ & $99(39.29)$ & $103(33.99)$ & \\
\hline $31-40$ & $48(19.05)$ & $53(17.49)$ & \\
\hline $41-50$ & $23(9.13)$ & $33(10.89)$ & \\
\hline $51-60$ & $17(6.75)$ & $14(4.62)$ & \\
\hline 60 and above & $11(4.37)$ & $19(6.27)$ & \\
\hline \multicolumn{4}{|l|}{ Gender } \\
\hline Male & $106(42.06)$ & $132(43.56)$ & \multirow[t]{3}{*}{$0.12(0.722)^{* *}$} \\
\hline Female & $146(57.94)$ & $171(56.44)$ & \\
\hline \multicolumn{3}{|l|}{ Ward } & \\
\hline CHEW & $1(0.4)$ & $1(0.33)$ & \multirow{7}{*}{$7.03(0.426)^{* *}$} \\
\hline A \&E & $0(0)$ & $1(0.33)$ & \\
\hline MMW & $4(1.59)$ & $7(2.31)$ & \\
\hline CHOP & $85(33.73)$ & $91(30.03)$ & \\
\hline ENT & $4(1.59)$ & $12(3.96)$ & \\
\hline FMW & $10(3.97)$ & $11(3.63)$ & \\
\hline Dermatology & $148(58.73)$ & $180(59.41)$ & \\
\hline
\end{tabular}

The distribution of fungal growth by demographic data is not statistically significant.

Table 3 shows the distribution of fungal species isolated in the patients. Aspergillus sp was the most common fungi isolated (41.67\%), followed by Candida sp (35.32\%) and Trichophyte sp (16.27\%). The least occurring fungi were Blastomyces spp (0.40\%) and Fusarium spp (0.40\%).

Table 3. Distribution of Isolated Fungi.

\begin{tabular}{lll}
\hline Fungal Growth & Frequency & Percentage (\%) \\
\hline Blastomyces spp & 1 & 0.40 \\
Fusarium spp & 1 & 0.40 \\
Arthrospore spp & 2 & 0.79 \\
Yeast & 3 & 1.19 \\
Dermaticious fungi & 5 & 1.98 \\
Penicillium spp & 5 & 1.98 \\
Trichophyte spp & 41 & 16.27 \\
Candida spp & 89 & 35.32 \\
Aspergillus sp & 105 & 41.67 \\
Total & 252 & 100.0 \\
\hline
\end{tabular}

\section{Discussion}

A five-year retrospective assessment of the pattern of fungal dermatoses investigations between 2015 to 2020 in the University of Port Harcourt Teaching hospital, located in southern Nigeria was done. The findings of the study showed a $45 \%$ prevalence of fungal growth in patients suspected to have fungal dermatoses. This is in contrast with the reports of Osaigbovo in Benin City, which observed a 31.3\% prevalence of fungal growth among patients referred for microbiological investigations for skin infections [1] However, the findings of the current study is consistent with the report of a similar study in Tanzania which reported a
$50.7 \%$ prevalence of fungal growth among patients referred for microbiological investigations of skin infections [7]. The relatively higher prevalence of fungal growth may be attributed to a myriad of environmental factors that could influence the occurrence of fungal infections of the skin. For instance, the study area is located in an Oil and gas hub which has been plagued with environmental challenges ranging from gas flaring to the continuous exposures of particulate and black soot [12-14].

The results of the current study showed that fungal growth was mostly occurring in individuals between $21-40$ years old. This could not be compared to relative findings of other studies as there is a paucity of information on the prevalence of fungal growth by various age groups in south-south states of Nigeria. However, the relatively higher occurrence of fungal growth among individuals between 21 - 40 years may be attributable to the higher distribution of the age group among patients that were suspected of skin infections and referred for laboratory diagnoses. Also this age bracket is in the active part of their life, therefore, the individuals may tend to sweat more which encourages the growth of fungal elements.

There was no significant association between fungal growth and gender distribution among the patients. This is consistent with the findings of similar studies which showed no association between occurrence of fungal growth in skin infections and gender $[3,5,15,16]$

The distribution of fungal growth among individuals that were 60 years and above was observed to be $6.27 \%$. This is relatively higher compared to the reports of Amadi et al., which showed a $3.1 \%$ prevalence of fungal growth among elderly people within a 10 -year period $(2006-2015)$ [6]. This is an indication that the occurrence of dermatophytosis among elderly persons nearly doubled within a 5 year period. Aspergillus sp was the most common fungi isolated (41.67\%), followed by Candida sp (35.32\%) and Trichophyte sp $(16.27 \%)$. The least occurring fungi were Blastomyces spp $(0.40 \%)$ and Fusarium spp $(0.40 \%)$. The findings of the study is consistent with reports of similar studies indicating that these three fungi are mostly associated with the occurrence of fungal skin infections in southern Nigeria [8, 13-15] The organisms have been associated with Superficial fungi skin infections that affect the skin, mucous membrane, nails, and hair.

\section{Conclusion}

Superficial fungi infections still need to be addressed as a public health problem among the growing populace of Nigeria. The favorable environment of hot and humid climate, poverty, poor sanitary conditions and overcrowding are well known factors that favor these fungi growth. The findings of the study show a relatively higher occurrence of fungal growth in skin infections in Port Harcourt, compared to other oil producing states of the country. Similarly, there seem to be an exponential increase in the prevalence of skin infections among elderly people in the period under review. 


\section{References}

[1] I. I. O. Prevalence and pattern of infectious dermatoses referrals to clinical microbiologists in a tertiary hospital in Southern Nigeria. African J Clin Exp Microbiol. 2019; 20 (2): $150-158$.

[2] Akinkugbe AO, Amira OC, Ozoh OB, Bandele E. Pattern of skin disorders in a rural community in Lagos State, Nigeria. Niger Heal J. 2016; 16 (2).

[3] Del Pozzo-Magaña BR, Lazo-Langner A, Gutiérrez-Castrellón P, Ruiz-Maldonado R. Common Dermatoses in Children Referred to a Specialized Pediatric Dermatology Service in Mexico: A Comparative Study between Two Decades. ISRN Dermatol. 2012; 2012: 1-5. doi: 10.5402/2012/351603.

[4] Odeibat H, Al-Tawara M, Omeish I. Patterns of Skin Diseases among Pediatric Patients Attending the Pediatric Dermatological Clinic at King Hussein Medical Center. $J R$ Med Serv. 2014; 21 (3): 38-45. doi: 10.12816/0005526.

[5] Shrestha D, Gurung D, Rosdahl I. Prevalence of skin diseases and impact on quality of life in hilly region of Nepal. $J$ Inst Med. 2013; 34 (3). doi: 10.3126/joim.v34i3.8917.

[6] Amadi ES, Belgam HI, Pepple EF. the Prevalence and Pattern of Dermatological Disorders. Niger J Med. 2017; 26 (1): 2328.

[7] Kiprono SK, Muchunu JW, Masenga JE. Skin diseases in pediatric patients attending a tertiary dermatology hospital in Northern Tanzania: A cross-sectional study. BMC Dermatol. 2015; 15 (1). doi: 10.1186/s12895-015-0035-9.

[8] Oninla OA. Superficial Fungi Skin Infections: The Bane of Dermatoses in Nigeria. J Med Microb Diagn. 2014; 3. doi: 10.4172/2161-0703.1000152.
[9] Emodi IJ, Ikefuna AN, Uchendu U, Duru A. Skin diseases among children attending the out patient clinic of the University of Nigeria teaching hospital, Enug. Afr Health Sci. 2010; 10 (4): 362-366. doi: 10.4314/ahs.v10i4.63844.

[10] Oyedepo JT, Katibi OS, Adedoyin OT. Cutaneous disorders of adolescence among nigerian secondary school students. Pan Afr Med J. 2020; 36: 1-10. doi: 10.11604/pamj.2020.36.36.21089.

[11] Connolly DM, Silverstein DI. Dermatology consultations in a tertiary care hospital: A retrospective study of 243 cases. Dermatol Online J. 2015; 21 (8).

[12] Altraide DD, Alex-Hart BA. Prevalence and Pattern of Skin Diseases among School Age Children at the University of Port Harcourt Teaching Hospital, Nigeria: A Hospital Based Study. Asian J Res Infect Dis. 2020; (1): 29-36. doi: 10.9734/ajrid/2020/v3i430134.

[13] Oninla OA, Oninla SO, Onayemi O, Olasode OA. Pattern of paediatric dermatoses at dermatology clinics in Ile-Ife and Ilesha, Nigeria. Paediatr Int Child Health. 2016; 36 (2): 106112. doi: 10.1179/2046905515Y.0000000012.

[14] Henshaw E, Ibekwe P, Adeyemi A, et al. Dermatologic Practice Review of Common Skin Diseases in Nigeria. Int $J$ Heal Sci Res. 2018; 8: 235. Accessed February 20, 2021. www.ijhsr.org.

[15] Henshaw EB, Olasode OA. Skin diseases in Nigeria: The Calabar experience. Int J Dermatol. 2015; 54 (3): 319-326. doi: $10.1111 /$ ijd.12752.

[16] Neupane S, Pandey P. Spectrum of Dermatoses among Paediatric Patients in a Teaching Hospital of Western Nepal. Nepal J Dermatology, Venereol Leprol. 2012; 10 (1): 20-26. doi: 10.3126/njdvl.v10i1.6419. 